

\title{
Unbequeme Vergangenheit
}

Antisemitismus, Judenverfolgung und Wiedergutmachung in Westfalen 1925-1965

Author: Marlene Klatt

In kaum zehn Jahren setzte das NS-Regime die völlige Isolierung der jüdischen Bevölkerung bis hin zu ihrer Deportation und Ermordung durch, ohne dass die Mehrheitsgesellschaft hiergegen nennenswerten Widerstand leistete. Wie es dazu kommen konnte, ist nach wie vor ein vieldiskutiertes Problem. Viel spricht dafür, eine Antwort im alltäglichen Zusammenleben von jüdischen und nichtjüdischen Deutschen zu su-chen. Das tut Marlene Klatt, am Beispiel der drei Gemeinden Arnsberg, Hagen und Niedermarsberg. Sie beschreibt den gewachsenen gesellschaftlichen Antisemitismus und zeigt konkret, welchen Anteil die lokale Gesell-schaft an der Verdrängung der jüdischen Minderheit aus dem öffentlichen Leben hatte. Auch der Nachgeschichte widmet sie sich. Wie weit gelang es der 'Wiedergutmachung', die Verfolgungstatbestände auszugleichen? Wie ernsthaft war dieser Versuch überhaupt und wie reagierten Opfer und Täter? Der Band untersucht zudem, was mit den 'arisierten' Vermögen geschah und wie man den Opfern nach 1945 begegnete. Ziel ist die Beantwortung der umstrittenen Frage, welchen Stellenwert die 'Wiedergutmachung' für jüdische Verfolgte in der deutschen Nachkriegsgesellschaft besaß und inwieweit die Opfer und ihr Schicksal von der Mehrheitsgesellschaft akzeptiert wurden.

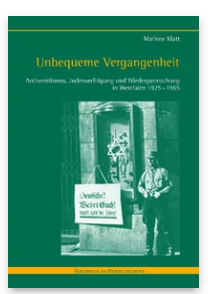

Pages: 508

Seiten

Language:

German

Subjects: Global

History, History

Publisher: Brill |

Schöningh

Series:

Forschungen zur Regionalgeschichte, Volume: 61

E-Book (PDF)

Released online: $\mathrm{O} 2 \mathrm{Mar} 2 \mathrm{O} 2 \mathrm{O}$

ISBN: 978-3-

657-76594-2

List price

USD $\$ 84.00$

Hardback

Publication date:

17 Jun 2009

ISBN: 978-3-

506-76594-9 
For more information see brill.com

Order information: Order online at brill.com +44330 333 0049 | customerservices@brill.com Submission information: brill.com/authors

Titles published by Brill | Fink, Brill | mentis or Brill | Schöningh: +49(o)715413279216| brill@brocom.de 